\title{
0 personagem no road movie documental brasileiro ${ }^{1}$
}

\section{Gustavo Souza}

\section{Resumo}

Este trabalho quer debater as composições de personagem no road movie documental brasileiro. Centrada nos filmes Pachamama (Eryk Rocha, 2009) e Olhe pra mim de novo (Cláudia Priscila e Kiko Goifman, 2011), a discussão apresenta três etapas: primeiramente, enfoca-se a forma como o personagem problematiza as composições dos gêneros cinematográficos e a própria noção de deslocamento. Em seguida, o debate sobre 0 personagem propõe uma ética da performance que guiaria as análises. E, por fim, a discussão se direciona para outros modos de ver o road movie realizado no Brasil.

\section{Palavras-Chave}

Personagem. Road Movie. Documentário.
Gustavo Souza | gustavo03@uol.com.br Professor do Programa de Pós-Graduação em Comunicação e Cultura Midiática da Universidade Paulista. Pós-doutor pela UFSCar. Doutor em Ciências da Comunicação pela ECA/USP.

\section{Introdução}

0 desejo de mobilidade, básico da condição humana, não demorou muito para chegar ao cinema. Mesmo antes da invenção da narrativa cinematográfica, realizadores viajaram para destinos longínquos em relação ao seu local de partida, lugares "exóticos", para filmar pessoas e seus hábitos. Surgiam, assim, os traveloges. Cerca de 60 anos depois, personagens de filmes como Bonnie and Clyde (Arthur Penn, 1967) e Easy rider (Dennis Hopper, 1969) invertem os papéis e passam a se deslocar, a viajar pela estrada, possibilitando a criação de um gênero cinematográfico em que essa questão seria abordada. Surgiam, assim, no contexto-norte americano, os road movies. ${ }^{2}$

0 enfoque deste trabalho se direciona, então, ao tema do deslocamento, com foco na viagem na estrada, especificamente no documentário brasileiro da primeira década do século 21. Nessa relação entre road movie e documentário, cabe a investigação de como 0 personagem se constitui e se apresenta, os impactos do deslocamento sobre ele e o debate 
sobre esses aspectos nos planos da narrativa

e da estética cinematográfica, pois esta interseção tem sido pouco explorada no campo do documentário.

Dois filmes compõem o corpus deste texto: Olhe pra mim de novo (Cláudia Priscila e Kiko Goifman, 2011) e Pachamama (Eryk Rocha, 2009). No primeiro, seu personagem central, Sillvyo Lucio, viaja pelo interior da região Nordeste, procurando se aproximar de distintas realidades conectadas pela falta de respeito e entendimento quanto às diferenças. 0 próprio Sillvyo, transexual masculino, é um exemplo concreto dessa questão. Pachamama, referência ao modo como os indígenas se referem à terra, narra a viagem do diretor Eryk Rocha e sua equipe ao Peru e à Bolívia para saber sobre um novo processo em que os povos excluídos da história experimentam, pela primeira vez, a representatividade na política. Contudo, o objetivo é também, nas palavras do diretor, "(...) pensar o Brasil, desde 0 começo. Como fazer um filme sobre 0 Brasil indo ao encontro da realidade vivida no Peru e na Bolívia?". 0 que conecta esses dois documentários com temáticas tão diferentes é 0 fato de se desenrolarem durante uma viagem na estrada. Isso faz com que ambos se inscrevam como road movies ou filmes de estrada, cujas características apontarei adiante. Aproximá-los é uma estratégia para construir uma discussão pautada, em um primeiro instante, na diferença, na desconexão, cuja justaposição revela, também, pontos de contato que fornecerão subsídios para o debate.

Por meio desses filmes, quero perceber quais configurações apresenta 0 personagem no documentário e suas reverberações no plano narrativo, discursivo e estilístico. Para isso, direciono o olhar a um contexto específico - 0 deslocamento em função de uma viagem -, pois talvez assim seja possível investigar tais personagens, dada a dificuldade de entender 0 indivíduo como uma globalidade social, ética, histórica e subjetiva. É evidente que na história do documentário há certas tendências que pontuaram o modo como pessoas eram trazidas para a cena. No caso brasileiro, desde o final dos anos 1990, aposta-se na subjetividade dos personagens (Fala tu, Canções), bem como na revelação do dispositivo de filmagem (Juízo, Rua de mão dupla), que, em muitos casos, põe

Versão atualizada do trabalho apresentado ao GT Estudos de cinema, fotografia e audiovisual do XXII Encontro Anual da Compós, na Universidade Federal da Bahia em junho de 2013. Agradeço aos colegas do GT pelas sugestões ao texto.

A fixação de datas para o surgimento de ciclos, correntes ou gêneros cinematográficos nem sempre é ponto pacífico. 0 cinema vivencia essa querela em seu próprio nascimento e com os road movies não é diferente. Embora ciente de que essa data e seus filmes correlatos sejam passíveis de discussão, acato a periodização convencional por tal aspecto não ser o foco do meu trabalho. Mais detalhes sobre a contestação da data-padrão para o surgimento dos road movies podem ser encontrados nos trabalhos de Samuel Paiva, especialmente no texto Gêneses do gênero road movie (2011). 
em evidência a relação entre a pessoa filmada e o documentarista (Santo Forte, Santiago), fazendo com que este último também se torne personagem (Um passaporte húngaro, 33). Mas isso não é suficiente, pois, diante da pluralidade de rotas que o documentário brasileiro tem percorrido nos últimos dez anos, aproximadamente, tal pluralidade se reverte, também, nos modos de composição e aparição dos personagens nos filmes. A diversidade da produção fornece um considerável número de documentários que merece ser investigado sob a ótica do deslocamento e da viagem - tema carente de estudos no cenário brasileiro.

0 que se verá está organizado em três partes. Primeiramente, debato como o personagem pode problematizar as composições dos gêneros cinematográficos, com foco no road movie, assim como ele relativiza também a própria noção de deslocamento, para além de sua instância física. Em seguida, concentrome na performance do personagem, buscando em autores como Schechner e Bakhtin as bases para propor uma ética da performance, que guiará as análises da constituição e da apresentação do personagem no documentário. E, por fim, discuto como a performance do personagem, em diversos encontros na estrada, encaminha o debate para a apreensão do road movie documental realizado no Brasil.

\section{Relativizações do gênero road movie e da noção de deslocamento}

0s documentários escolhidos fornecem, cada um a seu modo, pistas para um debate que problematiza o road movie como gênero cinematográfico. Antes de me deter nos filmes, cabe um breve mapeamento acerca das definições e características do road movie. Em um dos primeiros estudos sobre 0 gênero, que relaciona o road movie como um exímio fenômeno do pós-guerra, Corrigan (1991, p. 145) reconhece três características recorrentes: 1) ocorre uma quebra da estrutura familiar edipiana; 2) os acontecimentos na estrada incidem sobre os personagens: "o mundo histórico é sempre muito mais que um contexto, e os objetos ao longo da estrada são geralmente ameaçadores ou materialmente assertivos"3; 3) o protagonista passa a ter uma "identidade mecanizada" em decorrência do uso de moto ou do carro. Na introdução de The Road Movie Book, Cohan e Hark $(1997$, p. 1) defendem que o road movie apresenta "uma narrativa de viagem a partir de um particular conjunto de enredos e paisagens que impulsiona a liberação da estrada contra a opressão das normas hegemônicas". David Laderman vê o road movie como possibilidade de crítica cultural que "geralmente visa, além das fronteiras do conhecimento cultural, buscar uma revelação não familiar, ou pelo menos a emoção do desconhecido" (LADERMAN, 2002, p.1-2). 
Com ênfase na relação entre máquina e homem, Orgeron argumenta que o road movie "estende uma longa tradição cinematográfica, que postula uma mobilidade desacreditada e infeliz, num esforço para elogiar ou encontrar a estabilidade" (2008, p. 2, grifo do autor).

Todas essas definições tomam como referência filmes de estrada realizados nos Estados Unidos a partir da década de 1960, sendo caras, portanto, a um contexto sócio-histórico específico. Ainda assim, essa discussão é útil para se pensar o road movie realizado fora dos Estados Unidos, pois, via comparação, pode-se demarcar particularidades do filme de estrada feito na Europa ${ }^{4}$ ou na América Latina - aspecto que discutirei adiante. Por agora, essas definições convergem para 0 seguinte: o road movie é um tipo de filme cuja história se passa na estrada. De fato, não há novidade nessa constatação, mas não se pode esquecer que as ações na estrada, durante a viagem, são encabeçadas pelos personagens. Logo, se 0 personagem não se desloca, não há narrativa, não há história, não há road movie. Daí a importância de pensar o personagem no âmbito do road movie documental como uma instância particular do mundo histórico e com relação a ele próprio.

A primeira sequência de Olhe pra mim de novo é composta por um plano geral em que se vê uma estrada deserta, 0 céu, a vegetação do entorno e uma pessoa, de costas, à beira da estrada perto de uma cerca. Durante esse quadro, uma voz over diz o seguinte: "Olhe pra mim, olhe de novo, o que você vê? (...). Eu sou o homem que realiza qualquer mulher, eu sei o que é uma TPM foda, eu sei 0 que é a angústia da sensibilidade feminina quando a autoestima está baixa, mas eu sei 0 que é o tesão, a tara masculina da penetração, da pegada de um homem com uma mulher, eu sou completo, só me falta glamour". No término dessa fala, sabemos que a pessoa à beira da estrada é Sillvyo Lucio, personagem central do documentário.

A voz over é também utilizada por Eryk Rocha para nos apresentar a proposta de Pachamama. No plano visual, há uma câmera subjetiva de alguém que dirige na estrada. Ao longo dessas imagens, o diretor informa sobre os objetivos do filme e o modo como ele será realizado. Nesse momento, há uma ambiguidade sobre a atuação de Eryk como um personagem, pois, na medida em que situa a realização do documentário como um desejo pessoal, o que poderia colocá-lo como 0 epicentro da narrativa, ele sinaliza para 0 oposto disso ao informar sobre seu interesse nas pessoas que pretende encontrar. No desenrolar do filme, vê-se que Eryk é um realizador que narra seus propósitos, abrindo mão de um locutor profissional - uma prática que tem se tornado comum entre diversos documentaristas. Em 
nenhum momento Rocha se lança no papel de personagem, pois é personagem no documentário quem empresta sua imagem ou voz em uma ação integrada entre gesto e palavra para assim compor uma narrativa.

0 modo como Eryk Rocha aparece em Pachamama problematiza a própria noção de road movie, pois, ainda que 0 filme aconteça durante uma viagem, seus personagens são moradores das cidades por onde a equipe passou, ou seja, eles não se deslocam. Embora a voz over de Eryk exponha seus objetivos, 0 filme é composto de depoimentos e imagens colhidos durante a viagem. Há, assim, uma narrativa que se desloca, mas os seus personagens, não. Tendo em vista que no road movie o deslocamento na estrada é realizado pelos personagens do filme - a referência, neste caso, é notadamente a ficção, de onde emerge a discussão sobre esse gênero cinematográfico -, documentários como Pachamama abalam as delimitações impostas pelo gênero, pois 0 que impulsiona o deslocamento é um objetivo previamente traçado pelo documentarista, ao invés de questões materiais ou existenciais de alguém escolhido como personagem.

Pachamama possibilita que se pense o road movie no documentário com personagens fixos, que não se deslocam - o que, em um primeiro instante, pode parecer um contrassenso, mas que ressalta não somente as indeterminações dos personagens, como as particularidades do road movie documental.
Retomar a ficção é útil para melhor compreendêlo: no cinema ficcional, os personagens em deslocamento garantem a possibilidade do road movie; já no documentário, além do personagem que se desloca, a revelação dos métodos de filmagem faz com que a questão do deslocamento se estenda também ao modo como esta instância se dá no plano narrativo. Em sua vertente documentário, o road movie é capaz de transcender as "regras" traçadas pelo gênero, apontando para a necessidade de centrar-se, duplamente, nos personagens e na narrativa do filme. Em Pachamama, o deslocamento ocorre no plano narrativo, uma vez que 0 diretor revela quais são seus objetivos e como fará para executá-los; em Olhe pra mim de novo, ele pode ser visto tanto em seu personagem central, como no desenrolar da narrativa, que nos informa sobre as diferentes cidades por onde este personagem passa. Em virtude dessas ponderações, opto por não investigar a questão da viagem e do deslocamento no documentário brasileiro sob a ótica dos estudos de gênero. ${ }^{5}$ A discussão sobre o road movie como gênero serve aqui como uma porta de entrada para outras searas, como o estudo da composição do personagem, porém distanciada da tipificação genérica cara a esse campo (gângster, índio vilão, loira fatal, malandro, etc.).

Olhe pra mim de novo não chega a contestar a definição de road movie, pois, de fato, Sillvyo Lucio está em uma viagem pelo interior do Nordeste. Contudo, os planos da estrada, presentes no filme por oito vezes, surgem nos 
momentos em que o personagem relata em voz over momentos pessoais, cuja montagem os articula em uma sequência cronológica que vai da juventude à fase adulta. Nesses planos, Sillvyo é captado de longe, muitas vezes parado, de costas para a câmera, e a estrada tem pouca circulação de veículos (em três desses planos ela está completamente deserta), criando um contraste com a ideia de movimento e mudança, que é recorrentemente a ela associada no road movie de modo geral. 0 espaço é estático.

Cria-se um road movie em que o olhar do personagem é também estático, quase um antiroad movie. Nessas sequências, o deslocamento do personagem se dá pela ativação de um trabalho de memória que resgata momentos de sua trajetória, sinalizando, metaforicamente, para 0 movimento do personagem. É a "memória como trajetória" (WATERSON, 2007, p. 66-70) que promove 0 deslocamento. 0 compartilhamento de sua história de vida, registrado pela câmera, estende as trajetórias de transmissão da memória para além do tempo vivido por cada ser humano, afinal, como propõe Waterson (2007, p. 66), "as memórias não podem se tornar sociais até que se articulem, em qualquer meio de comunicação, e assim tornem-se disponíveis para serem compartilhadas". A fronteira que separa a intimidade de sua publicização torna-se obscura em função da exposição de uma história de vida que é particular, mas, ao mesmo tempo, parte do mundo histórico que, em muitos casos, resiste ao reconhecimento da alteridade como uma condição tácita do humano.

Dessa forma, o modo como os personagens aparecem nesses dois documentários conduz, de um lado, à apreensão do deslocamento para além de seu aspecto físico, dos corpos em movimento, permitindo 0 acesso a um universo narrativo e estilístico mais amplo; de outro, ajuda a relativizar a arquitetura dos gêneros cinematográficos, sinalizando para a necessidade de uma investigação mais aprofundada da maneira como tais personagens se constituem e se apresentam.

\section{$2 \mathrm{~A}$ performance do personagem}

Para estabelecer uma aproximação com 0 personagem em deslocamento no documentário brasileiro, recorro a outra aproximação: entre a teoria do documentário e os estudos de performance. Nesse cenário, interessa-me a perspectiva que privilegia a performance do personagem. Este aspecto foi debatido por Thomas Waugh, que foi, se não 0 primeiro, pelo menos um dos que mais se destacou no esteio dessa reflexão. Apoiado na história do documentário, ele formula três categorias analíticas para a compreensão da performance do personagem: uma da ordem da apresentação; outra, da representação, 
e uma híbrida, com características dessas duas. Segundo o autor, "a diferença entre a representação e a apresentação não é que uma utiliza a performance e a outra não, mas é que a primeira nega e esconde os componentes de sua performance, através de convenções como não olhar para a câmera, enquanto a segunda reconhece abertamente e explora essa possibilidade" (WAUGH, 2011, p. 79).

No contexto brasileiro, são poucos os estudos que se detiveram no personagem no documentário ${ }^{6}$. Mariana Baltar (2007) e Clara Ramos (2013) foram as autoras que, até 0 momento da redação deste trabalho, mais avançaram neste debate. Baltar utiliza o conceito de performance para discutir a imaginação melodramática operada por um conjunto de documentários brasileiros. ${ }^{7}$ Ramos também se interessa pela performance ao articular as intenções da pessoa filmada e as preferências narrativas do realizador para entender a construção dos personagens no documentário. Há também outros estudiosos que se voltam para 0 tema ${ }^{8}$, mas não é minha intenção fazer um extenso levantamento bibliográfico sobre esse tópico, e sim perceber como a reflexão já realizada contribui para 0 andamento da discussão.
Como se vê, não serei o primeiro a propor a noção de performance aplicada ao documentário. $\mathrm{E}$ para testar essa aplicação, retomo os filmes a partir de seus personagens. Como já dito, Sillvyo Lucio está viajando pelo interior do Nordeste, mas o documentário não explicita se a viagem faz parte de suas atividades profissionais ou se ela ocorreu em função da realização do filme. Sendo uma ocasião excepcional ou não, a viagem desse personagem aciona três diferentes modos em que a performance se desenvolve: 1) ele faz um balanço de sua história de vida - da juventude ao momento da realização do filme, cujo recurso utilizado é a sua voz over em sequências em que aparece parado à beira da estrada, quase se diluindo na paisagem; 2) Sillvyo encontra, ao longo da viagem, indivíduos marcados pela intolerância, assumindo o papel de entrevistador ao procurar saber sobre essas pessoas; 3) a reaproximação com sua filha Maria Tereza: no decorrer do documentário, ouvimos mensagens deixadas por Sillvyo Lucio na caixa postal do celular de sua companheira, Widna, as quais informam sobre a tentativa de convencimento de alguém que, no máximo, sabemos que é do sexo feminino, como se vê logo na abertura do filme: "oi, amor, tudo bem? Tô morrendo de saudade de você. (...) Ela me ligou, mas disse que não sabe se

Sobre o personagem no road movie documental não encontrei trabalhos a respeito.

A saber: Ônibus 174 (José Padilha, 2002), Um passaporte húngaro (Sandra Kogut, 2003), Peões (Eduardo Coutinho, 2004), A pessoa é para o que nasce (Roberto Berliner, 2004), Estamira (Marcos Prado, 2004) e Edifício Master (Eduardo Coutinho, 2002).

Bezerra (2014) se debruça especificamente sobre a investigação do personagem na filmografia de Eduardo Coutinho. 
vai participar da filmagem. Eu tô deixando ela à vontade, mas é importante que ela participe. Beijo, te amo muito". Mais para o final, o documentário revela que essa pessoa é Maria Tereza, filha que tivera na adolescência e que não aceita a condição transexual da mãe. A montagem de Olhe pra mim de novo intercala esses três blocos até culminar no encontro de Sillvyo Lucio com Maria Tereza.

Em Pachamama, há uma preocupação por parte de Eryk Rocha em se aproximar do contexto político da Bolívia e do Peru (o documentário foi realizado em 2007). A estratégia, nesse caso, é promover debates em lugares públicos como praças, ruas e até em um táxi. Pelo modo como o filme apresenta, a câmera foi posicionada em um local considerado estratégico e, com a aproximação das pessoas, os embates começaram a acontecer. Refiro-me a embates porque 0 documentário é montado basicamente dentre dessa chave. Diante de um tema proposto - por exemplo, se há uma "ditadura socialista" na Bolívia -, há opiniões divergentes, e Pachamama procura ouvir os dois lados.

A descrição dessas estruturas narrativas aponta para o modo como os personagens aparecem nos dois documentários. Tanto os moradores das cidades do Peru e da Bolívia, como Sillvyo Lucio e os personagens coadjuvantes de Olhe pra mim de novo retomam opiniões e práticas cotidianas preexistentes, embora, diante das câmeras, elas apareçam como únicas e inéditas. Essa aparente contradição entre o já conhecido e a novidade é o que caracteriza a performance, segundo o que propõe Richard Schechner. Esse autor se interessa pela performance para além das modalidades artísticas (teatro e dança, em especial) ao sugerir que a vida cotidiana é, em si, permeada constantemente por performances, principalmente se consideramos que:

toda a gama de experiências, compreendidas pelo desenvolvimento individual da pessoa, pode ser estudada como performance. Isto inclui eventos de larga escala, tais como lutas sociais, revoluções e atos políticos. Toda ação, não importa quão pequena ou açambarcadora, consiste em comportamentos duplamente exercidos (SCHECHNER, 2003, p. 27, grifos meus).

Esse "comportamento restaurado", para utilizar o termo de Schechner, caracteriza a performance dos personagens de Pachamama e Olhe pra mim de novo, seja, de um lado, pessoas opinando sobre a situação política do país (ou da cidade) onde vive; ou, de outro, por meio da análise que Sillvyo Lucio faz da influência negativa das religiões evangélicas frente à aceitação das diferenças. Esses discursos estão previamente concebidos por parte dos entrevistados, mas, diante do registro para a câmera, eles se tornam únicos e originais. Mas a questão não se resume ao que se fala. Nos primeiros instantes de Olhe pra mim de novo, Sillvyo visita uma ex-companheira adepta do candomblé. Ambos prestam seus depoimentos e, ao final da sequência, ele dança e canta no terreiro durante uma cerimônia. Ao restaurar esse ritual, ele atua para o documentário. Em Pachamama, há uma reza em que um xamã 
restaura também em um longo depoimento sobre si e o lugar onde mora. Nesses dois casos, há uma retomada de rituais cuja natureza é em si performática, reforçando ainda mais a dimensão de comportamento restaurado.

É válido ressaltar que Schechner não é 0 primeiro estudioso a se deter no que se pode chamar de "performance social". Trabalhos anteriores aos seus, como os de Goffman (2008), já propunham o entendimento da esfera cotidiana a partir da noção de performance. No entanto, Schechner está mais interessado nas elaborações que cada pessoa pode acionar (daí, a ideia de comportamento restaurado) do que nas circunstâncias de produção ou de recepção da performance (Goffman). Isso não implica que o contexto se descole da pessoa, mas, diante da necessidade de investigar o personagem em deslocamento no documentário, a contribuição de Schechner é mais efetiva, por estar centrada nas ações da pessoa.

Reconhecer que as atividades cotidianas são repetições de atos anteriormente executados é 0 primeiro passo a ser dado, mas é preciso ir além. Se a performance é da ordem do comportamento restaurado, o que se pode apreender no ato de restaurar? 0 primeiro ponto a se considerar é que o personagem no documentário pode ser uma construção tanto do documentarista quanto de si.
Ele é 0 entre-lugar resultante do encontro entre a pessoa e 0 documentarista. 0 segundo aspecto é que os personagens são pessoas com vidas e experiências anteriores e posteriores à realização do filme. Dessa forma, a seleção do que é dito ou realizado para a câmera ganha mais nitidamente uma dimensão de "evento único do ser" (BAKHTIN, 1997), que deve ser visto como um ato ético orientador do modo como cada indivíduo se situa no mundo. Essa ideia, empréstimo de Bakhtin, é válida para se pensar, no documentário, na fenda que se abre entre a pessoa em sua vida cotidiana e a pessoa agora personagem, permitindo analisá-lo não como categoria, mas a partir de sua individualidade e diversidade.

Assim sendo, a chave de leitura que proponho para o personagem no documentário está pautada em uma ética da performance, a qual se caracteriza pelo reconhecimento da retomada de ações e discursos cotidianos em momentos únicos como um ato ético em que vida e experiência compõem a narrativa. Aética da performance inclui a dimensão cotidiana em um debate que, em muitos casos, privilegia os sistemas representacionais, como o documentário ou o teatro. Uma perspectiva que não se situa, porém, dentro daquela que considera a dimensão ética como ponto nevrálgico do documentário, ou, quem sabe, a sua especificidade, até porque a ética precisa estar presente também na telenovela, no videoclipe, no 
telejornal, no cinema de ficção, etc., para citar apenas o campo midiático e audiovisual. Essa equação permite 0 seguinte encaminhamento: antes, discuti como o personagem contribui para o debate sobre os gêneros cinematográficos, bem como para a relativização da ideia de deslocamento. 0 movimento, nesse caso, é da instância do personagem para questões de maior porte. Agora, inverto o sentido, ao perguntar: como 0 deslocamento afeta o personagem? Como o filme revela essa dimensão?

\section{0 personagem na estrada}

Ao debater as fronteiras, a migração e 0 desenraizamento no cinema brasileiro dos anos 1990, França chama a atenção para a possibilidade dos encontros como um ponto de convergência de uma série de filmes realizados nesse período ${ }^{10}$ Pensando o documentário brasileiro dos anos 2000, Baltar argumenta que a performance do personagem se manifesta também pela "experiência do encontro" (BALTAR, 2010, p. 224, grifo meu), presente ou não no discurso fílmico. Como se verá a seguir, Pachamama e Olhe pra mim de novo corroboram essa perspectiva, cabendo, então, as perguntas: 0 que geram esses encontros? Como eles moldam os personagens?
A viagem de Sillvyo Lucio não busca apenas 0 encontro com grupos marcados pela intolerância, mas também com Maria Tereza, sua filha. Como sinalizado anteriormente, sabemos sobre essa personagem misteriosa por meio das mensagens deixadas por Sillvyo na caixa postal do celular de sua companheira. Maria Tereza hesita, mas aceita o convite para participar do documentário. Trata-se, inicialmente, de uma conversa tensa, pois, por não aceitar a transexualidade da mãe, cogitou um rompimento definitivo. Elas resgatam o passado, resumem os momentos difíceis em que disseram e ouviram "coisas duras", mas, ao mesmo tempo, não omitem o carinho e 0 amor que sentem uma pela outra. Tanto que Sillvyo justifica que a única pessoa que pode tratá-lo no feminino é a sua filha.

0 sentido da viagem para esse personagem é encaixar, no plano pessoal, a peça do complexo quebra-cabeças que é ser transexual em uma família e em uma comunidade que enxergam essa condição como uma anomalia. A estrada, para esse personagem, não tem o sentido da libertação ou escape, como sugerem muitos road movies, mas, inversamente, representa a possibilidade do encontro e do embate, e também da reconciliação, mesmo que para isso sua intimidade seja esgarçada. ${ }^{11}$

Os matadores (Beto Brant, 1997), Terra estrangeira (Walter Salles e Daniela Thomas, 1995), Estorvo (Ruy Guerra, 2000), Do outro lado do rio (Lucas Bambozzi, 2004). 
Ao estudar a intimidade no road movie, Stringer (1997) chama a atenção para o fato de que, apesar de específica, ela conduz também a interesses contextuais que muito dizem sobre 0 universo retratado. Expor aquilo que é íntimo torna-se uma estratégia eficaz para os objetivos do personagem, pois conduz, a partir de sua experiência pessoal, a um ato ético que lança luz sobre o terreno da esfera política, na luta por direitos de grupos tidos como minoritários. É nesse horizonte que a performance do personagem no documentário não se dissocia, como sugeriu Waugh, de uma dimensão ético-política, indicando também para uma mudança de eixo no modo como se costuma(va) ver o documentário. Postulada por Nichols (1991) como um aspecto-chave, a sobriedade do discurso documental cede espaço hoje, cada vez mais, para a construção de um discurso calcado nas emoções, ainda que atravessado por choques e discordâncias, como se vê em Olhe pra mim de novo no fraterno e bélico diálogo entre mãe e filha. Maria Tereza aceita 0 fato de a mãe se relacionar com mulheres, mas recusa a transformação do corpo e o comportamento masculino. Sillvyo Lucio é bastante didático em sua explicação para a filha, supondo que tal discurso já estivesse "pronto", sendo retomado (ou restaurado, para utilizar um termo schechneriano) não só porque ele sabe que esse confronto aconteceria, mas também pelo trabalho de conscientização que desenvolve.

Se a fronteira que Sillvyo Lucio precisa atravessar é metafórica, em Pachamama ela é material, literal, real. No texto em voz over da abertura, Eryk informa: "São dois países vizinhos que, com o Brasil, compõem uma tríplice fronteira. As fronteiras. Chegar às fronteiras. Romper as fronteiras. (...) Durante a viagem conversamos sobre a América do Sul (...). Que continente é esse? Que parte do continente é essa? A Amazônia, a selva, a cordilheira. Filmar, pensar, me deslocar, o filme, uma viagem. Tem a ver com a existência, o próprio deslocamento da existência". 0 que motiva a ida de Eryk Rocha ao Peru e à Bolívia é o desejo de conhecer uma realidade que, para nós, brasileiros, sempre pareceu distante, apesar de geograficamente próxima, afinal, esses países fazem fronteira com o Brasil. Essa relação distanciada é o que gera o filme, pois o Brasil permaneceu por muito tempo de costas para os seus vizinhos da América do Sul, gerando um desconhecimento sobre quem são, como vivem, o que pensam. Esse desconhecimento impulsiona Eryk Rocha, que, na montagem de Pachamama, não envereda pela construção de seus personagens como o outro-exótico, mas, inversamente, como aquele que responde às suas dúvidas. Ao filmar nas bordas - tanto reais quanto metafóricas, dada a posição desses dois países nos cenários latino-americano e mundial -, Pachamama explora a diversidade linguística, cultural e, principalmente, os pontos de vista políticos de seus personagens, distanciando-se de uma dimensão homogênea - muitas vezes, 0 destino irrefutável de quem ocupa uma posição desprivilegiada nas hierarquias. 0 filme preza pelo encontro com outra realidade, nem melhor nem 
pior, diferente, apenas; permitindo, por meio de seus personagens, a relativização de uma unidade política latino-americana. Pôr uma lupa sobre essa questão é um exercício em que converge a performance do personagem atrelada a um ato ético responsável por parte do realizador, na medida em que recusa enxergar esses espaços de modo idealizado ou romantizado.

Fronteiras muitas vezes são demarcadas com a intenção de proteger um "nós" em relação a "eles". Ou, segundo Bragança (2011, p. 15), foram por muito tempo também caracterizadas "pela corrupção, pela prostituição, pelo crime, pela degradação dos costumes". Não é o que se vê em Pachamama. Para além da boa recepção que peruanos e bolivianos dispensam a Rocha e sua equipe, ao atravessar as fronteiras entre países e cidades, o documentário oscila entre aquilo que aproxima e distancia tais personagens. As pessoas em Pachamama, prestando depoimento ou não, aparecem basicamente com o rosto em close. Essa opção reflete 0 desejo do diretor em se aproximar da realidade que se propõe a documentar, não somente no plano discursivo, mas também imagético. A proximidade do rosto revela que 0 entendimento do estatuto do personagem é, antes de tudo, uma questão de imagem, pois permite também a percepção de elementos não verbais. No caso de o personagem encarar a câmera, mas sem nada dizer, cria-se uma brecha entre aquilo que é visível, mas não necessariamente legível. Rocha passou por diversos lugares, fez registros que, se não fossem pelas legendas informando a cidade e o país, seria difícil para nós diferenciá-los a partir dos seus moradores. Essa dificuldade apresentada pelos closes nos rostos é um indício de que a fronteira (e o que está para antes e depois dela) é um espaço tênue, poroso, capaz de criar uma "zona de indiscernibilidade", pois ela "é aquilo que funda e articula espacialidades, criando suas próprias coordenadas, suas transversais, suas derivas" (FRANÇA, 2003, p. 28).

Tal aspecto é importante para se pensar as fronteiras no cinema contemporâneo, por sua dimensão simbólica e imaginada, como apontam alguns autores que se dedicam inclusive a debater o road movie..$^{12}$ Entretanto, alguns personagens de Pachamama, quando sabem que a equipe que os filma é brasileira, trazem o Brasil para o debate ao ressaltar que, economicamente, ele é uma potência, e cabe aos vizinhos lutarem para chegar ao mesmo patamar. Outro personagem afirma que os brasileiros são mais "civilizados" que os bolivianos no modo como resolvem suas diferenças. Seja no campo econômico ou cultural, esses depoimentos evidenciam que as fronteiras ainda são literais, palpáveis, materiais. Elas também ditam a ordem dos fatos, os rumos de cidadãos e as escolhas políticas, ainda que a fronteira metafórica 
- diluída e opaca - também seja passível de discussão. Sendo assim, os personagens de Pachamama, pelo modo como aparecem, por aquilo que falam, sugerem uma dialética das fronteiras, em que pesa tanto sua dimensão real quanto imaginada.

Na discussão que encaminha sobre o road movie latino-americano, Laderman afirma que uma diferença básica deste em relação ao filme de estrada norte-americano é a contraposição entre uma hiper-individualização do sujeito e uma busca por um significado autêntico de nação. Os filmes que permitiram ao autor chegar a essa constatação foram produzidos entre os anos 1960 e 1980, momento em que a América do Sul experimentava significativas transformações, especialmente na esfera política. Hoje, ao observar a produção "latina", por meio de filmes como Pachamama e Olhe pra mim de novo, vê-se uma superação dessa prerrogativa que articula as dimensões individuais e coletivas, pois é o desejo pessoal de Eryk Rocha que o conduz a um contexto mais amplo. Já Sillvyo Lucio estabelece uma viagem que conecta contextos mais ampliados a questões pessoais. Nesses dois documentários, o deslocamento na estrada busca, como vimos nas análises, o encontro com a alteridade, seja ela de gênero ou partidária.

\section{Considerações Finais}

Por se tratar do primeiro texto referente a esta pesquisa, quero terminar essa discussão propondo (mais) encaminhamentos para o futuro do que necessariamente conclusões definitivas. Para isso, é válido sublinhar que Pachamama e Olhe pra mim de novo retomam ao final dos filmes o percurso narrativo apresentado no início, 0 que acena para uma possibilidade de leitura do road movie documental brasileiro. No começo de Olhe pra mim de novo, Sillvyo Lucio vai a uma cartomante que fala sobre suas características e seu futuro. Em Pachamama, são inúmeras questões que movem Eryk Rocha, informadas por sua voz over. Ao término, há um travelling ao contrário que mostra o lugar que a equipe está deixando, porém sem narração. Ouvimos apenas uma música instrumental e 0 barulho de crianças que seguem o carro. No final de Olhe pra mim de novo, Sillvyo volta à cartomante que retoma 0 seu passado, mas aponta para o futuro, ao frisar 0 senso de liberdade como uma condição básica de sua existência.

\section{0 silêncio de Eryk Rocha e as sequências da} cartomante apontam que não é a busca por uma identidade nacional e tampouco um sujeito na contramão dos códigos sociais hegemônicos que caracteriza o filme de estrada documental brasileiro. 0 sentido do deslocamento aqui é pautado na dúvida sobre si e sobre o contexto com o qual se depara, em um esforço para construir um modo de olhar para o mundo, que é subjetivo, mas inteiramente relacional. Há uma conexão entre o conteúdo e 0 sentido de um dado ato e a realidade histórica de sua existência, como uma vivência experimentada 
uma única vez na performance dos personagens. 0 caráter transitório dos corpos em movimento, de passagem pela estrada, fixa uma presença, ou pelo menos a sugere, que instala crises, dilemas, instabilidades, lançando luz sobre as contradições desses personagens, que, com a estrada, constroem novas experiências, outras expectativas alicerçadas, antes de tudo, pelas dúvidas impostas pelo exterior e também por si.

\section{Referências}

BAKHTIN, Mikhail. Hacia una filosofia del acto ético. De los boradores y otros escritos. Porto Rico: Anthropos, 1997.

BALTAR, Mariana. Realidade lacrimosa: diálogos entre 0 universo do documentário e a imaginação melodramática. Niterói, Universidade Federal Fluminense. Tese de doutorado, 2007. Cotidianos em performance: Estamira encontra as mulheres de Jogo de cena. In: MIGLIORIN, Cezar (org.). Ensaios no real: o documentário brasileiro hoje. Rio de Janeiro: Azougue, 2010, p. 217-234.

\section{BEZERRA, Cláudio. A personagem no documentário} de Eduardo Coutinho. Campinas: Papirus, 2014.

BRAGANÇA, Maurício de. Cartografias latinoamericanas: fronteiras midiáticas de um continente em construção. Eco-Pós, Rio de Janeiro, vol. 14, nº 1, p. $1-16,2011$.

COHAN, Steven; HARK, Ina Rae (orgs.) The road movie book. Londres: Routledge, 1997.

CORRIGAN, Timothy. Cinema without walls: movies and culture after Vietnam. New Brunswick: Rutgers University Press, 1991.

FRANÇA, Andréa. Terras e fronteiras no cinema político contemporâneo. Rio de Janeiro: 7Letras, 2003.
Imagens da itinerância no brasileiro

contemporâneo. In: \& LOPES, Denilson (orgs.). Cinema, globalização e interculturalidade. Chapecó: Argos, 2010, p. 219-242.

\section{GOFFMAN, Erving. A representação do eu na vida} cotidiana. 15a ed. Petrópolis: Vozes, 2008.

LADERMAN, David. The road movie rediscovers Mexico: Alex Cox's Highway Patrolman. Cinema Journal. Austin, vol. 39, $\mathrm{n}^{0}$ 2, p. 74-99, 2000.

Driving visions: exploring road movie. Austin: University of Texas Press, 2002.

MAZIERSKA, Ewa; RASCAROLI, Laura. Crossing new Europe. Postmodern travel and the european road movie. Londres: Wallflower Press, 2006.

NICHOLS, Bill. Representing reality. Bloomington: Indiana University Press, 1991.

ORGERON, Devin. Road movies. From Muybridge and Méliès to Lynch and Kiarostami. Nova York: Palgrave Macmillan, 2008.

PAIVA, Samuel. Gêneses do gênero road movie. Significação - Revista de cultura audiovisual. São Paulo, ${ }^{0} 36$, p. 35-53, 2011.

RAMOS, Clara Leonel. A construção do personagem no documentário brasileiro contemporâneo: autorrepresentação, performance e estratégias narrativas. São Paulo, Universidade de São Paulo. Tese de doutorado, 2013.

SCHECHNER, Richard. 0 que é performance? 0 percevejo. Rio de Janeiro, ano 11, no 12, p. 25-50, 2003.

STRINGER, Julian. Exposing intimacy in Russ Meyer's Motorpsycho! and Faster pussycat! Kill!Kill!! In: COHAN, Steven \& HARK, Ina Rae (orgs.)

The road movie book. Londres: Routledge, 1997, p. 165-178.

WATERSON, Roxana. Trajectories of memory: documentary film and the transmission of testimony. 
History and Anthropology. Londres, vol. 18, $\mathrm{n}^{0} 1, \mathrm{p}$. 51-73, 2007.

WAUGH, Thomas. The right to play oneself: looking back on documentary film. Minneapolis: University of Minnesota Press, 2011. 
The carachter in the Brazilian road movie documentary

\section{El personaje en el documental road movie brasileño}

\section{Abstract}

This work aims to discuss the compositions of the characters in brazilian documentary road movie. For this, the discussion, from movies Pachamama (Eryk Rocha, 2009) and Olhe pra mim de novo (Cláudia Priscila e Kiko Goifman, 2011), has three steps: first, as the character questions the compositions of film genres, and it also relativizes the notion of displacement, beyond its physical instance. Then the debate about the character to propose an ethics of performance that would guide the analyzes. Finally, the routing of the discussion to other ways of seeing the road movie made in Brazil.

\section{Keywords}

Character. Road Movie. Documentary.

\section{Resumen}

Este trabajo pone en discussion las composiciones de lo personaje road movie de los documentales brasileños. Centradas en las películas Pachamama (Eryk Rocha, 2009) y Olhe para mim de novo (Cláudia Priscila e Kiko Goifman, 2011), la discusión se presenta en tres etapas: la primera, se enfoca la forma como el personaje discute las composiciones de los géneros cinematográficos, así como se relativiza la propria noción de desplazamiento. En la segunda, se debate como el personaje A continuación, el debate sobre el carácter al proponer una ética de la performance que guiarán los análisis. Y, por fin, la discussion se mueve para otros modos de ver el road movie hecho en Brasil.

\section{Palabras-Clave}

Personaje. Road Movie. Documental. 


\section{Expediente}

A revista E-Compós é a publicação científica em formato eletrônico da Associação Nacional dos Programas de Pós-Graduação em Comunicação (Compós). Lançada em 2004, tem como principal finalidade difundir a produção acadêmica de pesquisadores da área de Comunicação, inseridos em instituições do Brasil e do exterior.

\section{E-COMPÓS I www.e-compos.org.br I E-ISSN 1808-2599}

Revista da Associação Nacional dos Programas

de Pós-Graduação em Comunicacão.

Brasília, v.17, n.3, set./dez. 2014

A identificação das edições, a partir de 2008

passa a ser volume anual com três números.

\section{CONSELHO EDITORIAL}

Afonso Albuquerque, Universidade Federal Fluminense, Brasil Alberto Carlos Augusto Klein, Universidade Estadual de Londrina, Brasil Alex Fernando Teixeira Primo, Universidade Federal do Rio Grande do Sul, Brasil Ana Carolina Damboriarena Escosteguy, Pontifícia Universidade Católica do Rio Grande do Sul, Brasi

Ana Gruszynski, Universidade Federal do Rio Grande do Sul, Brasil Ana Silvia Lopes Davi Médola, Universidade Estadual Paulista, Brasil André Luiz Martins Lemos, Universidade Federal da Bahia, Brasi Ângela Freire Prysthon, Universidade Federal de Pernambuco, Brasil Antônio Fausto Neto, Universidade do Vale do Rio dos Sinos, Brasil Antonio Carlos Hohlfeldt, Pontifícia Universidade Católica do Rio Grande do Sul, Brasil Antonio Roberto Chiachiri Filho, Faculdade Cásper Líbero, Brasi Arlindo Ribeiro Machado, Universidade de São Paulo, Brasil Arthur Autran Franco de Sá Neto, Universidade Federal de São Carlos, Brasil Benjamim Picado, Universidade Federal Fluminense, Brasil César Geraldo Guimarães, Universidade Federal de Minas Gerais, Brasil Cristiane Freitas Gutfreind, Pontifícia Universidade Católica do Rio Grande do Sul, Brasil Denilson Lopes, Universidade Federal do Rio de Janeiro, Brasil Denize Correa Araujo, Universidade Tuiuti do Paraná, Brasil Edilson Cazeloto, Universidade Paulista, Brasil

Eduardo Vicente, Universidade de São Paulo, Brasil

Eneus Trindade, Universidade de São Paulo, Brasil

Erick Felinto de Oliveira, Universidade do Estado do Rio de Janeiro, Brasil Florence Dravet, Universidade Católica de Brasilia, Brasil

Gelson Santana, Universidade Anhembi/Morumbi, Brasi Gilson Vieira Monteiro, Universidade Federal do Amazonas, Brasil Gislene da Silva, Universidade Federal de Santa Catarina, Brasil Guillermo Orozco Gómez, Universidad de Guadalajara, México Gustavo Daudt Fischer, Universidade do Vale do Rio dos Sinos, Brasil Hector Ospina, Universidad de Manizales, Colômbia Herom Vargas, Universidade Municipal de São Caetano do Sul, Brasil leda Tucherman, Universidade Federal do Rio de Janeiro, Brasil Inês Vitorino, Universidade Federal do Ceará, Brasil Janice Caiafa, Universidade Federal do Rio de Janeiro, Brasil Jay David Bolter, Georgia Institute of Technology, Estados Unidos Jeder Silveira Janotti Junior, Universidade Federal de Pernambuco, Brasi João Freire Filho, Universidade Federal do Rio de Janeiro, Brasil John DH Downing, University of Texas at Austin, Estados Unidos
José Afonso da Silva Junior, Universidade Federal de Pernambuco, Brasil José Carlos Rodrigues, Pontifícia Universidade Católica do Rio de Janeiro, Brasil José Luiz Aidar Prado, Pontifícia Universidade Católica de São Paulo, Brasil José Luiz Warren Jardim Gomes Braga, Universidade do Vale do Rio dos Sinos, Brasil Juremir Machado da Silva, Pontifícia Universidade Católica do Rio Grande do Sul, Brasil Laan Mendes Barros, Universidade Metodista de São Paulo, Brasil Lance Strate, Fordham University, USA, Estados Unidos Lorraine Leu, University of Bristol, Grã-Bretanha Lucia Leão, Pontifícia Universidade Católica de São Paulo, Brasil Luciana Panke, Universidade Federal do Paraná, Brasil Luiz Claudio Martino, Universidade de Brasília, Brasil Malena Segura Contrera, Universidade Paulista, Brasil Márcio de Vasconcellos Serelle, Pontifícia Universidade Católica de Minas Gerais, Brasil Maria Aparecida Baccega, Universidade de São Paulo e Escola Superior de Propaganda e Marketing, Brasil Maria das Graças Pinto Coelho, Universidade Federal do Rio Grande do Norte, Brasil Maria Immacolata Vassallo de Lopes, Universidade de São Paulo, Brasil Maria Luiza Martins de Mendonça, Universidade Federal de Goiás, Brasil Mauro de Souza Ventura, Universidade Estadual Paulista, Brasil Mauro Pereira Porto, Tulane University, Estados Unidos Nilda Aparecida Jacks, Universidade Federal do Rio Grande do Sul, Brasil Paulo Roberto Gibaldi Vaz, Universidade Federal do Rio de Janeiro, Brasil Potiguara Mendes Silveira Jr, Universidade Federal de Juiz de Fora, Brasil Renato Cordeiro Gomes, Pontifícia Universidade Católica do Rio de Janeiro, Brasil Robert K Logan, University of Toronto, Canadá

Ronaldo George Helal, Universidade do Estado do Rio de Janeiro, Brasil Rosana de Lima Soares, Universidade de São Paulo, Brasi Rose Melo Rocha, Escola Superior de Propaganda e Marketing, Brasil Rossana Reguillo, Instituto de Estudos Superiores do Ocidente, México Rousiley Celi Moreira Maia, Universidade Federal de Minas Gerais, Brasi Sebastião Carlos de Morais Squirra, Universidade Metodista de São Paulo, Brasil Sebastião Guilherme Albano da Costa, Universidade Federal do Rio Grande do Norte, Brasil

Simone Maria Andrade Pereira de Sá, Universidade Federal Fluminense, Brasi Suzete Venturelli, Universidade de Brasília, Brasil

Tiago Quiroga Fausto Neto, Universidade de Brasília, Brasil

Valerio Fuenzalida Fernández, Puc-Chile, Chile

Veneza Mayora Ronsini, Universidade Federal de Santa Maria, Brasi Vera Regina Veiga França, Universidade Federal de Minas Gerais, Brasil

\section{COMISSÃO EDITORIAL}

Cristiane Freitas Gutfreind I Pontifícia Universidade Católica do Rio Grande do Sul, Brasil Irene Machado I Universidade de São Paulo, Brasil

Jorge Cardoso Filho I Universidade Federal do Recôncavo da Bahia, Brasil Universidade Federal da Bahia, Brasil

CONSULTORES AD HOC

Adriana Amaral, Universidade do Vale do Rio dos Sinos, Brasil

Alexandre Rocha da Silva, Universidade Federal do Rio Grande do Sul, Brasi

Arthur Ituassu, Pontifícia Universidade Católica do Rio de Janeiro, Brasil

Bruno Souza Leal, Universidade Federal de Minas Gerais, Brasil

Elizabeth Bastos Duarte, Universidade Federal de Santa Maria, Brasil

Francisco Paulo Jamil Marques, Universidade Federal do Ceará, Brasi

Maurício Lissovsky, Universidade Federal do Rio de Janeiro, Brasil

Suzana Kilpp, Universidade do Vale do Rio dos Sinos, Brasil

Vander Casaqui, Escola Superior de Propaganda e Marketing, Brasil

EDIÇ̃̃O DE TEXTO E RESUMOS I Press Revisão

SECRETÁRIA EXECUTIVA I Helena Stigger

EDITORAÇÃo ELETRÔNICA I Roka Estúdio
COMPÓS I www.compos.org.br

Associação Nacional dos Programas de Pós-Graduação em Comunicação

Presidente

Eduardo Morettin

Universidade de São Paulo, Brasil

eduardomorettin@usp.br

Vice-presidente

Inês Vitorino

Universidade Federal do Ceará, Brasil

ines@ufc.br

Secretária-Geral

Gislene da Silva

Universidade Federal de Santa Catarina, Brasil

gislenedasilva@gmail.com 